\title{
Interpretações de Adam Smith pela Escola Austríaca de Economia*
}

\author{
Wesley Reynolds ${ }^{* *}$
}

\begin{abstract}
Resumo: Mesmo aceitando a racionalidade científica e a teoria do laissez-faire defendidas por Adam Smith, os economistas da Escola Austríaca, ampliaram o escopo da Ciência Econômica ao romper com os pressupostos objetivos do Iluminismo, adotando uma visão subjetiva da ação humana dos agentes econômicos. Ao longo do texto o autor apresenta os diversos pontos de divergência e de convergência entre as concepções de Adam Smith e de pensadores como Carl Menger, Eugen von Böhm-Bawerk, F. A. Hayek, Henry Hazlitt, Ludwig von Mises e Murray N. Rothbard.

Palavras-Chave: Adam Smith, Economia Clássica, Escola Austríaca, Teoria do Valor Trabalho, Sociedade Contratual.
\end{abstract}

\section{Interpretations of Adam Smith through the Austrian School of Economics}

\begin{abstract}
Even accepting the scientific rationality and the theory of laissez-faire advocated by Adam Smith, economists of the Austrian School broadened the scope of Economic Science while they disrupted the objective assumptions of Enlightenment, adopting a subjective view of human action of economic agents. Throughout the text the author presents several points of divergence and convergence between the ideas of Adam Smith and thinkers as Carl Menger, Eugen von Böhm-Bawerk, F. A. Hayek, Henry Hazlitt, Ludwig von Mises and Murray N. Rothbard.
\end{abstract}

Keywords: Adam Smith, Classical Economics, Austrian School, Labor Theory of Value, Contract Society.

Classificação JEL: B12, B25

\footnotetext{
" Artigo original em inglês, enviado exclusivamente para o periódico MISES: Revista Interdisciplinar de Filosofia, Direito e Economia.

Traduzido do original em inglês para o português por Flávio L. Alencar.

** Wesley Reynolds é professor adjunto de História da Northwood University e guia histórico da Midland County Historical Society, ambas na cidade de Midland, em Michigan, nos EUA. Cursou a graduação em História no Thomas Edison State College, em Trenton, New Jersey, e o mestrado em História na Central Michigan University, em Mount Pleasant, Michigan, tendo escrito uma dissertação sobre os levantes jacobitas na Grã-Bretanha, entre os anos de 1688 e 1745. Foi assessor de programas educacionais do Mackinac Center for Public Policy, em Midland, e pesquisador do Russell Kirk Center for Cultural Renewal, em Mecosta, Michigan. É membro da World History Association, da American Historical Association e da Historical Society of Michigan. Além das atividades de magistério, atualmente está escrevendo um livro sobre a história da cidade de Midland, entre os anos de 1890 e 1930.

E-mail: reynolds@computermail.net
} 
A Escola Austríaca de Economia desenvolveu-se a partir da teoria do laissez-faire, do moralista e economista escocês Adam Smith (1723-1790), sem, contudo, sucumbir à ingenuidade econômica do moralista e economista escocês. À semelhança de Francis Bacon (1561-1626), John Locke (1632-1704) e do próprio Adam Smith estudiosos austríacos apoiam-se em uma crença na existência de leis científicas que determinam a economia. Grande parte da sua argumentação tem um sabor pós-iluminista, embora não deixem de criticar os filósofos iluministas. Tanto Smith quanto a Escola Austríaca esteiam suas teorias na supremacia de uma economia do "estado de natureza". No entanto, os economistas austríacos mudam a ênfase dos pressupostos objetivos do pensamento iluminista para o funcionamento subjetivo de cada um dos membros de uma economia, e expandem a ciência econômica até incluir a ciência da praxeologia. As teorias de Adam Smith sobre o valor e o trabalho são particularmente preocupantes para os economistas austríacos. Embora seu trabalho frequentemente mergulhe na tradição básica de Smith, os teóricos austríacos tanto refinaram quanto criticaram o método deste pensador escocês.

\section{I - Adam Smith: Sentimentos E RiqueZA}

Assim como Jean-Jacques Rousseau (1712-1778) defendeu um "estado de natureza" social para o homem, Adam Smith propôs um argumento de "estado de natureza" dentro da economia nacional. Este "estado de natureza" depende mais dos sentimentos morais dos seres humanos livres que da orquestração forçada de governos com suas abordagens mercantilistas. $\mathrm{O}$ ataque de Smith contra o mercantilismo envolveu uma teoria sobre a divisão natural do trabalho e o valor atribuído dos bens econômicos. O pensador escocês deu o nome de "mão invisível" à ordem por trás das interações livres dentro deste sistema.
A simpatia constitui a base para o argumento de Adam Smith sobre a aplicação livre dos sentimentos morais. Em sua Theory of Moral Sentiments [Teoria dos Sentimentos Morais], publicada originalmente em 1759, Smith afirma que a simpatia naturalmente deriva das impressões geradas em nossos sentidos ao colocarmo-nos na situação dos sofrimentos trágicos dos outros. Por meio da imaginação, os homens substituem as suas faculdades pelas faculdades de outros a fim de medir a experiência dos outros; seus olhos pela visão do outro, ou sua própria audição pelos ouvidos de outro, etc. O acordo emocional entre o simpatizante e o simpatizado só existe quando o simpatizante evoca virtudes mais suaves, como condescendência sincera, e o simpatizado exibe virtudes mais difíceis, como o espírito de sacrifício ${ }^{1}$. A beneficência ou benevolência, ao contrário de justiça, não pode ser forçada, porque, por definição, é sempre livre. Além disso, a falta de beneficência não produz um mal positivo, e não pode ser punida racionalmente como tal. Pelo contrário, deve ser impingida justa punição em caso de desrespeito e violação da justiça, a fim de compensar o dano². A concepção de Smith de um livre mercado repousa sobre suas distinções complementares de justiça forçada e benevolência voluntária.

Adam Smith argumentava que a busca da riqueza origina-se de uma busca de utilidade, uma vez que a utilidade de um objeto possui a beleza desse objeto. Aumentar os usos humanos dos oceanos, multiplicar a quantidade de cidades, casas e comunidades, e até a melhoria nas artes, demonstram o fato

${ }^{1}$ SMITH, Adam. The Theory of Moral Sentiments. In: HEILBRONER, Robert L. \& MALONE, Laurence J.(Ed.). The Essential Adam Smith. New York: W. W. Norton \& Company, 1987. p. 65-76. [N. do T.: Substituiremos todas as referências à obra pelas passagens equivalentes em língua portuguesa da seguinte tradução brasileira: SMITH, Adam. Teoria dos Sentimentos Morais. Trad. Lya Luft. São Paulo: Martins Fontes, 1999. (Primeira Parte, Seção I, Capítulos I-V), p. 5-28].

${ }^{2}$ SMITH. Teoria dos Sentimentos Morais. (Segunda Parte, Seção II, Capítulos I-II), p. 97-106. 
de que os ricos buscam a abundância, e assim escolhem apenas os melhores recursos disponíveis.

Escolhem os ricos apenas os mais seletos lotes de terra, os melhores materiais, a arte mais refinada; deixa-se, porém, aos trabalhadores, ironicamente, todo o resto para possuírem ${ }^{3}$. Esta divisão de trabalho segmenta a sociedade em partes economizadoras, e à maravilha desta ordem humanamente inconsciente Smith nomeou "mão invisível". Ao invés de serem humanamente manipuladas por um "rei filósofo", as atividades quotidianas da vida mundana, racionais ou não, formam a organização da economia ${ }^{4}$.

Em The Wealth of Nations [A Riqueza das Nações], publicada originalmente em 1776, Adam Smith afirma que a divisão do trabalho decorre não de planejamento humano, mas da crescente inclinação humana para a troca de mercadorias. Os homens precisam da ajuda uns dos outros, a fim de viverem em uma sociedade civilizada, mas não podem depender inteiramente da benevolência. Smith afirma que um açougueiro não alimenta os outros por um desejo de ser benevolente, mas por causa de seu interesse pessoal. Os clientes do açougueiro recebem carne do açougue, $\mathrm{e}$ dão em troca algo ao açougueiro ${ }^{5}$. Da mesma forma, Smith argumenta que os comerciantes designarão como moeda algumas mercadorias que trocam facilmente dentro do mercado de câmbio. Porque um indivíduo não pode satisfazer as suas necessidades em uma sociedade com divisão de trabalho, Smith conclui

\footnotetext{
${ }^{3}$ Idem. Ibidem., (Quarta Parte, Capítulos I-II), p. 219-36.

${ }^{4}$ Idem. Ibidem., (Quinta Parte, Capítulo I), p. 239-46.

${ }^{5}$ SMITH, Adam. An Inquiry into the Nature and Causes of the Wealth of Nations. University Park: The Penn State Electronic Classics Series Publication, 2005. p. 18-19. [N. do T.: As referências à obra serão substituídas pelas passagens equivalentes em língua portuguesa da seguinte edição brasileira: SMITH, Adam. A Riqueza das Nações: Investigação sobre sua Natureza e suas Causas. Apres. Wiston Fritsh; Intr. Edwin Cannan, Trad. Luiz João Baraúna. São Paulo: Abril Cultural, 1983. 2v. (Livro I, Capítulo II), Vol. I, p. 49-51].
}

que o valor objetivo de um bem no sistema de trocas é igual ao trabalho investido no bem para levá-lo ao mercado 6 . A base lógica de Smith para o valor objetivo dos bens é severamente contestada pela Escola Austríaca.

Outra área de controvérsia para os economistas austríacos é a visão de Adam Smith sobre a tributação, particularmente no que diz respeito à sua primeira máxima sobre o assunto. Smith escreveu:

Os súditos de cada Estado devem contribuir o máximo possível para o sustento para a manutenção do Governo, em proporção a suas respectivas capacidades, isto é, em proporção ao rendimento de que cada um desfruta, sob a proteção do Estado. As despesas de governo, em relação aos indivíduos de uma grande nação, são como as despesas de administração em relação aos rendeiros associados de uma grande propriedade, aos quais são obrigados a contribuir na proporção aos respectivos interesses que têm na propriedade? ${ }^{7}$.

Assim sendo, Smith propunha que cada membro da sociedade deveria contribuir para o Estado na mesma proporção dos benefícios que este membro recebe do Estado. De maneira muito parecida a um inquilino, os membros da sociedade deveriam pagar pelos custos da grande "propriedade" do governo na medida em que recebem diversas vantagens da existência do Estado. Smith simplesmente parte do princípio de que uma estimativa objetiva do valor é possível.

\section{III - A CRÍTICA AUSTRÍACA}

Em seus Grundsätze der Volkswirthschaftslehre [Princípios de Economia Política], publicado originalmente em 1871, Carl Menger (1840-1921), fundador da Escola Austríaca de Economia, defende firmemente a existência

\footnotetext{
${ }^{6} \mathrm{SMITH}$, Adam. A Riqueza das Nações. (Livro I, Capítulos IV-V), Vol. I, p. 57-75.

${ }^{7}$ Idem. Ibidem. (Livro V, Capítulo II, Parte 2ª, \$1), Vol II, p. 247-48.
} 
de leis naturais que governam a ciência da economia, e critica as visões de Adam Smith sobre o trabalho e valor. Em seu prefácio, Menger argumenta que a economia é uma ciência que depende dos fenômenos da vida econômica, ordenados por leis definidas ${ }^{8}$. No primeiro capítulo, Menger afirma que uma conexão causal determina que o progresso humano começa com uma necessidade humana e termina com as propriedades necessárias para a transferência do bem que seja capaz de satisfazer essa carência. Outrossim, o conhecimento humano da carência e de suas propriedades de transferência incentivam a busca do domínio deste bem, de tal forma que possa ser direcionado para a satisfação das necessidades. Propriedade é a soma desses bens que um indivíduo economizador possui para a satisfação das suas necessidades 9 .

Carl Menger acreditava que a explicação de Adam Smith para a divisão gradual do trabalho era excessivamente simplista. Citando o exemplo de uma tribo australiana, Menger observa que a divisão gradual do trabalho é apenas um dos muitos fatores que determinam o progresso econômico e o aumento de bens de consumo disponíveis. Menger se deu conta de que as economias primitivas tomam como pressuposto que os bens mais fáceis de recolher são aqueles oferecidos pela natureza. Não só uma nova divisão do trabalho é necessária para fazer progredir tal economia, como também é preciso para o desenvolvimento de tal economia um abandono total de sua forma primitiva, uma investigação para combinar as propriedades de transferência em um processo informal de produção e a posse dessas propriedades ${ }^{10}$.

8 MENGER, Carl. Principles of Economics. Trad. James Dingwall e Bert F. Hoselitz. New York: New York University Press, 1976. p. 47-48. [N. do T.: Ao longo do artigo, utilizaremos como referência as páginas da seguinte edição brasileira: MENGER, Carl. Princípios de Economia Política. Intr. de F. A. Hayek; Trad. Luiz João Baraúna. São Paulo: Abril Cultural, 1983. p. 241].

${ }^{9}$ MENGER, Carl. Princípios de Economia Política. p. 243-44, 258.

${ }^{10}$ Idem. Ibidem., p. 256-57.
Além disso, Menger explica que o valor de uma mercadoria é determinado pela satisfação particular que esse bem traz consigo, ao invés de estar diretamente ligado à quantidade de trabalho necessária para atender a essa satisfação, como Smith argumentava. Menger resume a questão argumentando que, se um diamante foi cuidadosamente extraído de uma mina de diamantes ou se foi encontrado acidentalmente com pouco trabalho, isso é irrelevante para seu valor. Poucos consumidores se perguntam sobre a história do trabalho requerido para a produção antes de comprar um produto. Este histórico revelaria em que medida a produção de um bem foi economicamente apropriada para a atividade humana na História, mas não exerce uma influência necessária sobre o valor do bem ${ }^{11}$.

Em 1883, Carl Menger continuou sua crítica a Adam Smith no livro intitulado Untersuchungen über die Methode der Sozialwissenschaften und der politischen Ökonomie insbesondere [Investigações sobre o Método das Ciências Sociais com Especial referência à Economia Política]. Primeiro, Menger afirmou que Smith e seus seguidores não têm uma base segura para a sua teoria da economia, e que a crença predominante de que a ciência econômica pode chegar à perfeição é falsa ${ }^{12}$.

No entanto, Carl Menger elogia muito Adam Smith por não confundir a história da economia com a sua teoria. Menger admirava-o por compreender que a economia não estava totalmente motivada pelo interesse pessoal, e por não confundir investigações que partem do ponto de vista do interesse pessoal com o dogma de que o interesse pessoal é a mola mestra de toda ação humana ${ }^{13}$. Contextualizando o iluminismo francês bem como o escocês, Menger argumenta que as recomendações de Voltaire (1694-1778) para a melhoria

${ }^{11}$ Idem. Ibidem., p. 304-06.

${ }^{12}$ MENGER, Carl. Investigations Into the Methods of the Social Sciences with Special References to Economics. Trad. Francis J. Nock. New York: New York University Press, 1985. p. 27-28.

${ }^{13}$ Idem. Ibidem., p. 88. 
institucional na França não devem ser interpretadas como uma recomendação universal para todos os tempos e lugares, e que Smith viu a importância vital da História, das condições espaciais e dos fatores temporais para a ciência da economia. Voltando atrás em sua crítica inicial ao moralista e economista escocês, Menger cita o argumento de Eduard Baumstark (1807-1889) de que a economia, como campo de estudo, perde-se quando abandona o método de Adam Smith e de Adam Ferguson (1723-1816) de examinar historicamente o comércio, a cultura e o Estado especialmente relevantes para cada doutrina econômica. Em uma palavra, Baumstark acreditava que a economia perdeu sua base histórica quando os economistas abandonaram uma narrativa econômica como a iniciada por Smith e Ferguson; Menger elogia esta opinião de Baumstark. Menger acrescenta, porém, que Smith necessitava apenas desenvolver esta abordagem mais a fundo, quando afirma que "... nem mesmo o fundador da nossa ciência foi poupado de subestimar o valor dos estudos históricos para a nossa ciência e do absolutismo ahistórico..." ${ }^{\prime 14}$. O que Smith começou deve ser expandido para uma análise histórica detalhada do sistema econômico cultural, ou o campo da economia será condenado ao defeito absolutista de épocas anteriores. Menger exigia uma visão mais ampla do valor e do trabalho, que fosse além do tratamento original de Smith durante o início do laissez-faire, e acreditava que Smith era apenas o ponto de entrada no campo da economia.

Formulando sua própria história intelectual do desenvolvimento do campo da economia, Eugen von Böhm-Bawerk (1851-1914), em seu livro Kapital und Kapitalzins: Geschichte und Kritik der Kapitalzins-theorien [Capital e Juros: Uma História Crítica da Teoria Econômica], publicado em 1884, contou com o Iluminismo para uma explicação do juro. Tratando da origem das conceituações acadêmicas sobre o juro, Bohm-Barwerk elogia Francis Bacon pela compreensão dos juros como uma

\footnotetext{
${ }^{14}$ Idem. Ibidem., p. 168-69.
}

necessidade econômica, e por não cair na velha suposição de que o juro fosse antinatural. No entanto, Böhm-Bawerk critica Bacon por aceitar os juros apenas com base na conveniência. Cita os Sermones Fideles de Bacon: "Uma vez que é necessário que os homens deem e tomem dinheiro emprestado, e uma vez que eles são tão duros de coração... que eles não o emprestarão de outra maneira, não há nada a fazer senão permitir o juro" ${ }^{\prime 15}$. Esta linha de argumentação autoevidente, que perdurou por todo o Iluminismo, ignorou a questão de por que o o fenômeno do juro existe. A resposta de Bacon de que os homens são obrigados por necessidade de emprestar evitava o imperativo de provar a razão pela qual os homens são obrigados por necessidade a emprestar.

Böhm-Bawerk considerava John Locke como o único filósofo do século XVII capaz de fornecer uma explicação satisfatória sobre os juros. Citou o folheto de Locke Some Considerations of the Consequences of lowering the Interest and raising the Value of Money [Algumas Considerações sobre as Consequências da Redução dos Juros e da Elevação do Valor da Moeda]: "o dinheiro... é uma coisa estéril, e não produz nada; mas, em poucas palavras, transfere o ganho que era a recompensa do trabalho de um homem para o bolso de outro homem"16. Independentemente do arranque cínico de Locke, Böhm-Bawerk, disse que Locke justificava o juro por perceber que a distribuição desigual provoca tanto os juros do empréstimo quanto a renda da terra. Assim como um terratenente contrata com um arrendatário para cultivar suas terras sobrantes, um homem rico contratará um inquilino para o seu dinheiro. Além disso, o mutuário consentirá em pagar os juros porque, como um arrendatário de terras, ele pode produzir mais em um determinado valor do que a taxa de juros estipulada ${ }^{17}$.

\footnotetext{
${ }^{15}$ B ÖHM-B AWERK, Eugen von. Capital and Interest: A Critical History of Economical Theory. Trad. William Smart. New York: London and Macmillan and Co., 1980. p. 33-34.

${ }^{16}$ Idem. Ibidem., p. 44-45.

${ }^{17}$ Idem. Ibidem., p. 45.
} 
Ao tratar de Adam Smith, Böhm-Bawerk observava que nenhum fundador de um sistema científico pode compreender plenamente até mesmo os princípios mais fundamentais do sistema que está explorando. Destarte, Böhm-Bawerk considerava Smith como um bom início de uma viagem para o problema econômico do juro: acreditava que Smith não houvera esquecido a questão, mas que tampouco a trabalhara de forma satisfatória. Böhm-Bawerk concordava com o argumento de Smith de que o capital deve gerar lucro; caso contrário, o capitalista não investiria o seu dinheiro na contratação de trabalhadores ${ }^{18}$. De qualquer forma, Böhm-Bawerk também observava que uma afirmação tão simples não pode ser considerada uma teoria completa. Argumentava que em Smith faltou um esforço intelectual por descobrir as motivações psicológicas do interesse pessoal do credor, e os preços fixos de mercado que determinam a disparidade entre os custos e produtos ${ }^{19}$. A observação simplista de Smith, não diferentemente da confiança de Bacon em supostas verdades autoevidentes, apenas arranhou a superfície de um estudo sobre o juro.

Ainda assim, com o advento do século XX, a Escola Austríaca apoiou-se mais e mais no modo de raciocínio usado por Smith para popularizar eficazmente sua abordagem econômica de livre mercado. Em seu artigo The Use of Knowledge in Society [O Uso do Conhecimento na Sociedade], de 1945, F. A. Hayek (1899-1992) descreveu um "mecanismo", ou ordem espontânea semelhante à mão invisível de Smith, que regula a efetiva alocação de recursos para atender a demanda. Em primeiro lugar, ele destacou o problema do planejamento central, a indisponibilidade de conhecimento. Antes da construção de uma ordem econômica racional poder começar, um planejador central deve adquirir todas as informações relevantes, descobrir um sistema comum de preferências, e possuir total conhe-

\footnotetext{
${ }^{18}$ Idem. Ibidem., p. 70-71.

${ }^{19}$ Idem. Ibidem., p. 71.
}

cimento dos meios disponíveis ${ }^{20}$. No entanto, Hayek argumenta que os dados para o cálculo econômico não podem ser "dados" a uma só mente. Uma vez que os dados necessários apenas existem em fragmentos dispersos de conhecimento contraditório e incompleto guardados por indivíduos, Hayek argumenta que a dificuldade econômica da sociedade não é a forma de distribuir recursos "dados", mas sim como assegurar a utilização mais vantajosa de recursos conhecidos apenas pelos membros dispersos da sociedade, e por ninguém em sua totalidade ${ }^{21}$.

Hayek não se opunha ao planejamento econômico, mas apenas ao planejamento central. Ele fazia diferença entre planejamento central (um plano unificado para dirigir todo o sistema econômico), competição (o planejamento descentralizado de indivíduos separados), e planejamento intermediário pela indústria monopolizada ${ }^{22}$. Como a "mão invisível" de Adam Smith, Hayek apresenta o sistema de preços como um "mecanismo" para a ordem, sem conhecimento total. O indivíduo possui apenas as informações mais relevantes de preço, e como uma máquina, o preço regula as mudanças variáveis de escassez, relacionando apenas a informação vital para os produtores ${ }^{23}$. No entanto, Hayek faz questão de comentar sobre a imperfeição deste mecanismo:

Naturalmente, esses ajustes provavelmente nunca serão "perfeitos" no sentido em

20 HAYEK, Friedrich August von. The Use of Knowledge in Society. American Economic Review, Vol. XXXV, No. 4; (September, 1945): 519-30. [N. do T.: Substituiremos todas as referências à obra pelas passagens equivalentes em língua portuguesa da seguinte tradução brasileira: HAYEK, Friedrich August von. O Uso do Conhecimento na Sociedade. Trad. Philippe A. Gebara Tavares. MISES: Revista Interdisciplinar de Filosofia, Direito e Economia, Vol. I, No. 1 (jan.-jun. 2013): 153-62. Ver, particularmente: p. 154, 159-61].

${ }^{21}$ HAYEK. O Uso do Conhecimento na Sociedade. p. 154.

${ }^{22}$ Idem. Ibidem., p. 154-55

${ }^{23}$ Idem. Ibidem., p. 159-61. 
que o economista os conceberia em sua análise de equilíbrio, mas temo que os nossos hábitos teóricos de abordar o problema, supondo um conhecimento mais ou menos perfeito da parte de quase todas as pessoas, já nos tornou, de alguma forma, cegos para a verdadeira função do mecanismo de preços, e nos levou a aplicar padrões, a bem de verdade, enganadores, ao julgar sua eficiência ${ }^{24}$.

Para Hayek, a pior conclusão a tirar da imperfeição do mecanismo de preços é a necessidade de um plano central. Tal solução nunca poderia reunir a diversidade de conhecimento individual necessário para o sucesso do planejamento.

Henry Hazlitt (1894-1993) reformula o problema econômico de F. A. Hayek sobre o planejamento central de uma forma mais urgente quando afirma em seu livro Economics in One Lesson [Economia numa Única Lição], de 1946, que "o dia de hoje já é o amanhã que os maus economistas, ontem, nos aconselharam a ignorar" 25 . Acreditando que a tragédia da economia depois da Segunda Guerra Mundial era uma consequência de longo prazo devida a economistas que criticavam a poupança em escala nacional, Hazlitt argumentava que a economia podia ser resumida em um princípio: "A arte da economia está em considerar não só os efeitos imediatos de qualquer ato ou política, mas, também, os mais remotos; está em descobrir as consequências dessa política, não somente para um único grupo, mas para todos eles" ${ }^{\prime 26}$. Como ilustração deste princípio, Hazlitt explicava que os projetos de obras públicas para além de serviços públicos essenciais e voltados para a construção de emprego geral dependem de

\footnotetext{
${ }^{24}$ Idem. Ibidem., p. 160.

${ }^{25}$ HAZLITT, Henry. Economics in One Lesson. New York: Harper \& Brothers Publishers, 1946. p. 4-5. [N. do T.: As passagens da obra serão substituídas pelas equivalentes da seguinte edição brasileira: HAZLITT, Henry. Economia numa Única Lição. Trad. Leônidas Gontijo de Carvalho. São Paulo: Instituto Ludwig von Mises Brasil, 4ª ed., 2010. p. 24].
}

${ }^{26}$ HAZLITT. Economia numa Única Lição. p. 24. impostos; na medida em que o projeto representa um resultado visível, as despesas com imposto representam uma perda invisível na exata proporção monetária ao custo do projeto $^{27}$.

De qualquer maneira, algumas despesas do governo não dependem de tributação, mas de empréstimos ou de imprimir mais dinheiro. Henry Hazlitt reiterou mais uma vez a necessidade de se considerar o fato de longo prazo de que o governo não pode contrair empréstimos para sempre sem pagar as suas dívidas e, citando Adam Smith, "quando as dívidas nacionais chegaram a acumular-se até certo grau, creio quase que não houve um só caso de terem sido pagas de modo razoável e completo" 28 . Hazlitt acreditava, como Smith, que o bem-estar geral de uma nação é composto pelo bem-estar individual de cada um dos seus membros, e não vice versa. Mais uma vez Hazlitt cita Smith: "O que é prudência na condução de cada família privada [...] dificilmente será loucura na condução de um grande reino"29. Simplificando a economia em um princípio, Hazlitt concretizou ideias de Smith sobre a dívida e o investimento privado no contexto tanto das consequências aparentes da atividade econômica quanto das invisíveis.

Ludwig von Mises (1881-1973), em sua obra magna Human Action [Ação Humana], de 1949, desenvolveu a ciência da praxeologia, ou o estudo da ação humana. Em vez de envovler apenas preferências, para Mises a ação é o comportamento total de um homem, distinta da definição tradicional de trabalho. Ação implica a utilização de meios para atingir os fins. Trabalho muitas vezes é a forma pela qual a ação humana se manifesta, mas, em certos casos, até mesmo palavras podem satisfazer os fins desejados ${ }^{30}$. Semelhante à

\footnotetext{
${ }^{27}$ Idem. Ibidem., p. 37-42.

${ }^{28}$ Idem. Ibidem., p. 172.

${ }^{29}$ Idem. Ibidem., p. 189.

${ }^{30}$ MISES, Ludwig von. Human Action: A Treatise on Economics. Irvington-on-Hudson: The Foundation for Economic Education, 1996. 12-13. [N. do T.: Ao longo do artigo, utilizaremos como referência as páginas da
} 
noção de Hayek de conhecimento econômico subjetivo, Mises concebeu a praxeologia como uma preocupação com os fins subjetivos de significados humanos propositais, ao invés de como significado objetivo do curso de eventos concretos ${ }^{31}$. A partir desta definição de praxeologia, Mises considera as metas econômicas dentro do contexto de vidas humanas individuais, e não como um objetivo nacional ou uma aspiração central.

De todo modo, Ludwig von Mises não se sente compelido a concordar com Adam Smith em sua justificativa para a economia de livre mercado. Ele criticava como impossível a ideia inicial de Smith de que conspirações eficazes de empregadores podem manter os salários baixos. Revertendo completamente a defesa convencional para as regulamentações estatais garantidoras de níveis salariais justos, Mises explicava que os empregadores só serão capazes de explorar os trabalhadores se barreiras institucionais ao empreendedorismo forem erguidas. Mises elabora sua posição:

Se não se impedir o surgimento de novos empresários ou a expansão dos já existentes, qualquer queda nos preços dos fatores de produção dissonante da estrutura do mercado enseja, necessariamente, novas oportunidades de se obterem lucros. Aparecem logo pessoas querendo aproveitar-se da margem entre o nível de salários existente e a produtividade marginal do trabalho; sua demanda por mão de obra fará com que os salários voltem ao nível compatível com a produtividade marginal do trabalho. A combinação tácita entre os empregadores a que se referiu Adam Smith, mesmo que tivesse existido, não poderia reduzir os salários abaixo do nível estabelecido pelo mercado, a não ser que para se ter acesso à atividade empresarial viesse a ser necessário não apenas a inteligência e o capital (este último está sempre disponível para empresas capazes de

seguinte edição brasileira: MISES, Ludwig von. Ação Humana: Um Tratado de Economia. Trad. Donald Stewart Jr. São Paulo: Instituto Ludwig von Mises Brasil, 3a ed., 2010. p. 52-53].

${ }^{31}$ MISES. Ação Humana. p. 68. dar maiores retornos), mas também algum tipo de título institucional, uma carta patente, ou uma licença que só fosse concedida a pessoas privilegiadas ${ }^{32}$.

Aqui, Mises explica que, sem leis restritivas, as empresas vão naturalmente seguir o caminho para o maior lucro, rapidamente preenchendo as lacunas momentâneas de exploração usadas por outros empregadores, e trazer os preços salariais de volta para o valor de mercado. Mises previu que os mecanismos naturais de preço funcionariam sem a necessidade da intervenção sintética de Smith.

Construindo a partir da ciência econômica da praxeologia, de Ludwig von Mises, Murray N. Rothbard (1926-1995) contrasta uma sociedade contratual com uma sociedade hegemônica em seu Man, Economy, and the State [O Homem, a Economia e o Estado], de 1962, fazendo referência direta à mão invisível de Adam Smith. Para Rothbard, a forma básica da mão invisível depende de associação voluntária. Ele afirma que, por meio de troca indireta, uma sociedade contratual é uma sociedade cooperativa, na qual cada indivíduo é especializado na tarefa que melhor lhe cabe e, servindo a si mesmo na profissão de sua escolha, beneficia também os outros. O sistema econômico que inclui a produção de cada membro para a troca é cooperativo, na medida em que depende da iniciação voluntária dos seus membros, sem coerção ${ }^{33}$. Ao contrário de uma sociedade hegemônica, na qual uma pessoa ou grupo explora o todo, uma sociedade contratual permite que, por meio da escolha praxeológica, cada indivíduo beneficie os outros, independentemente de seus motivos. Para Rothbard, a maravilha desta verdade levou Smith a descrever a sociedade contratual como parecendo ter uma mão invisível por trás dela. Ao invés de evo-

\footnotetext{
${ }^{32}$ Idem. Ibidem., p. 679-80.

${ }^{33}$ ROTHBARD, Murray N. Man, Economy, and State: A Treatise on Economic Principles with Power and Market: Government and the Economy. Auburn: Ludwig von Mises Institute, 2009. p. 99-100.
} 
car um conceito de "sentimento de pertença" para a origem da sociedade, Rothbard preferia pensar a formação contratual da sociedade como racional, afirmando: "As pessoas reconhecem, por meio do uso da razão, as vantagens da troca, resultado da maior produtividade da divisão do trabalho, e elas passam assim a seguir este caminho vantajoso" ${ }^{\prime 34}$. A descrição de Rothbard de comportamento estabeleceu uma base racional para o intercâmbio.

Não obstante, Murray Rothbard criticou os economistas, começando por Adam Smith, que tentaram justificar um imposto progressivo por meio do princípio do benefício. De acordo com a teoria do benefício, o governo deveria tributar cada indivíduo no valor exato dos benefícios que ele recebe do serviço público. Rothbard fez uma crítica devastadora: já que os receptores do serviço não o recebem no contexto de um mercado livre, não há nenhuma maneira real de se calcular se o benefício existe realmente ou não. O benefício só existe dentro das opiniões arbitrárias de funcionários. Além disso, se os impostos anulam o valor do serviço, tanto o intercâmbio quanto o serviço se tornam desnecessários ${ }^{35}$. O esforço envolvido no intercâmbio (de impostos por serviços) é desperdiçado. É por isso que, em uma sociedade contratual, os indivíduos só investem em projetos que praxeologicamente produzem mais do que o esforço e o capital combinados.

Em sua obra complementar intitulada Power and Market [Governo e Mercado] de 1970, Murray Rothbard reitera essa crítica a Adam Smith. O objetivo do princípio tributário do benefício é evitar o pesado fardo do imposto, imitando o sistema de preços de mercado, e estabelecer um imposto neutro, distribuindo o imposto de acordo com o benefício que o indivíduo recebe do programa do referido imposto. Sistemas tributários de benefício tentam alcançar justificativas praxeológicas por meio da formulação de um critério de pagamento sem sacrifício. Smith

\footnotetext{
${ }^{34}$ Idem. Ibidem., p. 100.

${ }^{35}$ Idem. Ibidem., p. 923-24.
}

confundiu capacidade de pagamento com benefício, argumenta Rothbard ${ }^{36}$. Supondo que um indivíduo se beneficia do governo na proporção de sua renda, Smith presume que a renda do indivíduo determina a sua capacidade de pagamento, e, portanto, tributar esta habilidade é uma compensação adequada para os benefícios do Estado. Contudo, Rothbard fez a seguinte pergunta retórica: Como os ricos colhem mais benefícios do Estado do que os pobres simplesmente por ganhar mais? Rothbard continua: tanto na defesa civil quanto no bem-estar social, os ricos beneficiam-se menos do que os pobres, uma vez que os ricos podem pagar por segurança privada ${ }^{37}$. Ao contrário, argumenta Rothbard:

Se todos tivessem de pagar em conformidade com o benefício recebido, é claro que (a) os destinatários dos benefícios de "bem-estar" arcariam com os custos totais destes benefícios: os pobres teriam que pagar pelos próprios subsídios (incluindo, é claro, o custo extra do pagamento à burocracia para fazer as transferências), (b) os compradores de qualquer serviço público seriam os únicos contribuintes, de modo que os serviços públicos não poderiam ser financiados por um fundo fiscal geral, e (c) pela proteção da polícia, um homem rico pagaria menos do que um homem pobre, $\mathrm{e}$ menos em valores absolutos ${ }^{38}$.

Rothbard conclui que, de acordo com uma aplicação coerente do sistema de benefício, o bem-estar governamental iria contra seu próprio propósito ${ }^{39}$. Criticando Smith por sua posição sobre os regimes tributários,

${ }^{36}$ Idem. Ibidem., p. 1236. [N. do T.: As referências à obra serão substituídas pelas passagens equivalentes em língua portuguesa da seguinte edição brasileira: ROTHBARD, Murray N. Governo e Mercado: A Economia da Intervenção Estatal. Pref. Edward P. Stringham; Trad. Márcia Xavier de Brito e Alessandra Lass. São Paulo: Instituto Ludwig von Mises Brasil, 2012. p. 174].

${ }^{37}$ ROTHBARD. Governo e Mercado. p. 174-75.

${ }^{38}$ Idem. Ibidem., p. 175.

${ }^{39}$ Idem. Ibidem., p. 175-77. 
Rothbard deixa clara sua preferência por uma sociedade contratual.

\section{IV - CoNCLUSÃo}

Sem dúvida, os estudiosos austríacos submetem as contribuições teóricas da economia de Adam Smith ao escrutínio de um campo moderno de estudo econômico. Por uma questão de contexto, muito das concepções fundamentais de Smith sobre o valor e o trabalho não se podem realizar em um mundo industrial e pós-industrial. Ao mesmo tempo em que desafiava os pontos de vista de Smith sobre trabalho e valor, Carl Menger recomendava a forma básica da narrativa econômica histórica de Adam Smith. Eugen von Böhm-Bawerk criticava a argumentação autoevi- dente de Francis Bacon e afirmava que as observações simples de Adam Smith sobre os juros dificilmente podem ser consideradas uma teoria utilizável.

Não obstante, F. A. Hayek e Henry Hazlitt aproveitaram-se, direta ou indiretamente, das observações de Adam Smith sobre a mão invisível em contraste com o Estado. Ao deslocar o debate para permitir uma atividade mais subjetiva, Ludwig von Mises dissipou o conceito de salário de Adam Smith, e definiu a ciência da praxeologia.

Por fim, Murray Rothbard redefiniu a economia como uma aspiração por uma sociedade contratual ideal. A Escola Austríaca derivou-se de Adam Smith sem, contudo, forçar seus argumentos tradicionais em um mundo pós-industrial.cos 